\title{
Next steps for understanding the selective relevance of female-female competition
}

\author{
Kristal E. Cain ${ }^{1 *}$ and Kimberly A. Rosvall ${ }^{2}$ \\ ${ }^{1}$ Evolution, Ecology and Genetics, Research School of Biology, Australian National University, Acton, ACT, Australia \\ ${ }^{2}$ Department of Biology, Indiana University, Bloomington, IN, USA \\ *Correspondence: kristalcain@gmail.com; www.kecain.weebly.com
}

Edited by:

Devi Meian Stuart-Fox, University of Melbourne, Australia

Reviewed by:

Michelle L. Hall, University of Melbourne, Australia

Michael M. Kasumovic, The University of New South Wales, Australia

Keywords: competitive traits, costs and benefits, Bateman gradient, social selection, ornamentation, sex differences, intrasexual competition, sexual selection

\section{INTRODUCTION}

After decades of neglect, recent empirical research on exaggerated female traits (e.g., ornaments, armaments, aggression, acoustic signals, etc.) has revived interest in this widespread but poorly understood phenomenon, and shown that these traits often function in the context of femalefemale competition (West-Eberhard, 1983; Amundsen, 2000; Clutton-Brock, 2009; Rosvall, 2011a; Stockley and BroJørgensen, 2011; Rubenstein, 2012 [Theme issue]; Stockley and Campbell, 2013 [Theme issue]). However, recent reviews have emphasized the applicability of sexual vs. social selection, rather than rigorously examining the role of different ecological contexts in shaping the evolution of traits used in competitive contexts (hereafter, "competitive traits") in females. Thus, we still lack a solid understanding of the ecological and evolutionary mechanisms driving the evolution of female trait expression, in particular whether, how, and why these mechanisms vary among species, and between the sexes.

It is our opinion that two critical issues impede our understanding the evolution of competitive traits in females. (1) The field has yet to investigate the ecological and evolutionary mechanisms that underlie interspecific and intersexual variation in the expression of these traits. This is perhaps due to a perceived "apples and oranges" problem stemming from the observation that animals compete over a wide variety of resources that vary by species or sex. However, by focusing on the relationships between fitness currencies and the resources over which animals compete, we can empirically compare the strength and direction of selection across species and sexes. (2) To date, research has primarily focused on the fitness costs or benefits of female competitive traits. As with many questions in behavioral and evolutionary ecology, quantifying how costs and benefits interact is essential to furthering our understanding of the evolution of competitive traits. Here, our goal is to draw attention to these solutions in order to spur more efficient and transformative progress.

\section{APPLES vs. ORANGES: THEY'RE BOTH FRUIT!}

One of the biggest perceived difficulties in understanding the diversity of competitive traits is the challenge of contrasting species and sexes that differ in the nature of resources over which individuals compete, i.e., mates (sexual selection) vs. "ecological resources," such as nest sites, territories, or dominance rank (social selection) (WestEberhard, 1983; LeBas, 2006; Rosvall, 2011a; Stockley and Bro-Jørgensen, 2011; Tobias et al., 2012). Further, animals may compete over resources that vary in quantity or quality. Understanding how this competition influences the evolution of competitive traits across species, sexes, mating systems, ecologies, and life histories requires a renewed focus on fitness currencies that are directly comparable across these groups and contexts.

Sexual selection research has a long history of assessing selection on competitive traits in males by relating the number of mates to the number of offspring, i.e., the Bateman gradient (Bateman, 1948), and using these gradients to understand interspecific variation in the expression of sexually selected traits. While Bateman gradients have been applied to females (see Gerlach and Ketterson, 2013), they may be of limited utility when female productivity is limited by access to ecological resources, rather than mates. As several authors have suggested, mates are just one type of resource, and other forms of social competition can favor the expression of competitive traits (West-Eberhard, 1983; LeBas, 2006; Clutton-Brock, 2009; Rosvall, 2011a; Stockley and Bro-Jørgensen, 2011; Cain and Ketterson, 2012; Tobias et al., 2012).

By extension, we can generate modified gradients that relate resource acquisition to reproductive success or survival, in a sex and resource neutral manner (Figure 1, top panels). This approach allows us to quantify the selection gradient on competitive traits in relation to any resource, including but not limited to mates. In doing so, we can contrast the strength and direction of selection among species or between the sexes. The utility of these gradients clearly depends on measures of fitness that transcend species differences in the nature of competition. The benefits of female-female competition may not be fully captured by some immediate proxies of fitness, e.g., the number of mates or eggs (Clutton-Brock, 2009; Stockley and Bro-Jørgensen, 2011; Tobias et al., 2012), in part because certain benefits may accrue over longer time periods 


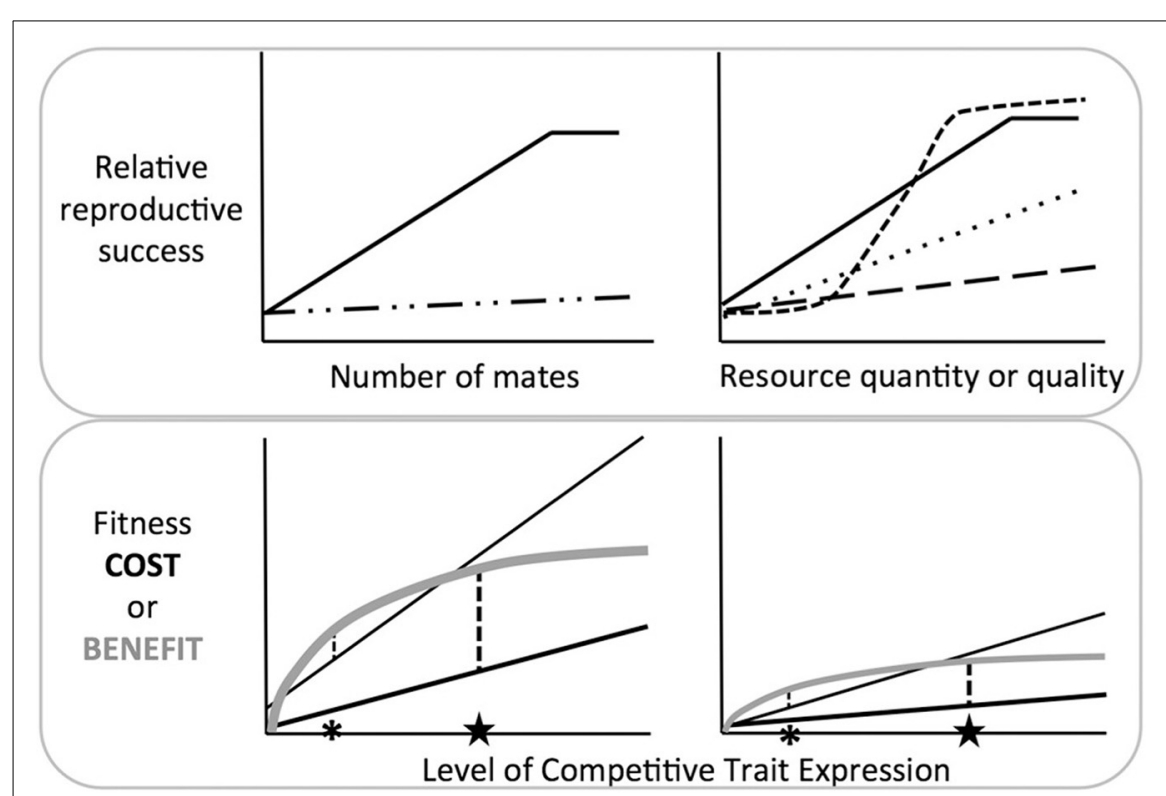

FIGURE 1 | Top Panel: Contrasting traditional selection gradients in relation to mate number (i.e., Bateman gradients, left) and modified selection gradients in relation to resource quantity or quality (right). The number of mates may predict female reproductive success in some species (e.g., polyandrous species, left panel; solid line), but generally there is no such relationship (left panel; dashed line), and female-female competition is therefore presumed to have little benefit. In contrast, the right panel depicts modified gradients, i.e., the relationship between reproductive success and resource acquisition. Species with different ecologies or life histories are now represented by a series of dashed lines. The dotted line could represent species where females compete for resources that vary in quality, or resources that influence offspring survival or success (e.g., oviposition sites or breeding territories). The steep dashed line could represent species where female competition influences many components of survival and reproductive success (e.g., competition for rank), or species where there are clear winner and losers (e.g., nesting cavities). The shape of these lines reveals that competition for resources may be advantageous even when there is little reason for mate competition. Bottom panel: Interactions between costs and benefits: Costs (black) and benefits (gray) interact to influence the optimal level of trait expression, i.e., the point where net benefits are maximized (asterisks or stars). In each panel, there are two species or populations that experience equivalent fitness benefits from increased trait expression, but different costs, and trait expression differs accordingly. In both cases, it is the interaction of costs and benefits-rather than either in isolation - that determines whether the optimal level of trait expression is low (asterisk) or high (star). Benefit and cost curves might also be separately assessed in relation to survival and reproduction (not shown), allowing insights into how trait expression affects different components of fitness.

(e.g., enhanced offspring rank or survival). Forward progress will thus require that we prioritize the difficult task of accurately measuring lifetime reproductive success or grand-offspring production. When these common currencies are used in the modified gradients in Figure 1, we can characterize the true effects of competition, and the field will be well poised to better understand how competitive traits evolve.

\section{QUANTIFYING BENEFITS AND COSTS}

Costs are central to many concepts in behavioral and evolutionary ecology, including the evolution of competitive traits (Zahavi, 1975; Hamilton and Zuk, 1982; Andersson, 1994). Indeed, the presumed (large) magnitude of these costs is a major reason why female competitive traits were historically assumed to be non-functional (see Amundsen, 2000; Tobias et al., 2012). In contrast, recent work has emphasized benefits without considering costs, leaving an empirical gap regarding the relative roles of costs vs. benefits and survival vs. reproductive success in driving trait expression. Explicit consideration of both costs and benefits is a fundamental approach in evolutionary ecology, and it is necessary for decomposing selection gradients to understand why competitive traits are favored or disfavored.

By examining how costs and benefits interact, it becomes apparent that exaggerated trait expression may be the result of large fitness benefits, or modest benefits paired with low costs (Figure 1, bottom panel, stars). Similarly, low levels of trait expression may be due to high costs, or moderate costs paired with low benefits (Figure 1, bottom panel, asterisks). Whether costs temper trait expression in females in a manner similar to males, and the extent to which female competitive traits are truly costly will remain open questions until this approach is put to greater use (see Simmons and Emlen, 2008; Bell et al., 2011; Rosvall, 2011b; Cain and Ketterson, 2013). Further, measuring these costs and benefits in the context of survival and reproduction in females from diverse species will reveal how variation in female life history and ecology alters these selective forces. Because females often compete for ecological resources that may increase survival, natural and social selection may often be aligned, rather than in opposition, as is frequently the case in males.

\section{MOVING FORWARD}

Regardless of whether females express competitive traits due to sexual selection or social selection (Clutton-Brock, 2009; Rosvall, 2011a; Tobias et al., 2012), a clearer understanding of the evolution of competitive phenotypes will emerge when we focus on the fitness consequences of competition, independent of the nature of the resource over which individuals compete. Further, examining the relationship between costs and benefits will provide insights that cannot be achieved by examining either alone.

Forward progress on these issues will shed light on fundamental questions in evolutionary biology. For instance, how will environmental change affect expression of competitive phenotypes? As the climate changes and species distributions shift, changes in resource availability might alter the benefit curve, while changing predator or disease regimes might modify the cost curve, altering population dynamics, mating systems, and ultimately phenotypic evolution. Further, our approach may uncover why females 
express particular forms of competitive traits but not others. Might the prevalence of aggression, ornaments, or vocal signals and the relative rarity of armaments in females (Tobias et al., 2012) relate to the costs of particular trait modalities? While benefits may determine whether and to what extent females express any competitive trait, the costs associated with different life histories or habitats may be more important for shaping trait modality. These are critical empirical questions that can be assessed by incorporating the perspectives described here.

\section{ACKNOWLEDGMENTS}

The authors would like to thank the organisers, participants and attendees of the Behavior 2011 symposium, Female Competition for Breeding Resources: Traits, Mechanisms and Modes of Selection (www.indiana.edu/ kettlab/ FemaleCompetition2011). We would also like to thank the editor, reviewers, NE Langmore, and ED Ketterson for providing valuable insight. KEC was supported by an NSF GRFP, DDIG (0910036), and Australian Endeavour Award; KAR was supported by an NIH R21HD073583.

\section{REFERENCES}

Amundsen, T. T. (2000). Why are female birds ornamented? Trends. Ecol. Evol. 15, 149-155. doi: 10.1016/S0169-5347(99)01800-5

Andersson, M. (1994). Sexual Selection. Princeton, NJ: Princeton University Press.

Bateman, A. J. (1948). Intra-sexual selection in Drosophila. Heredity 2, 349-368. doi: 10.1038/hdy.1948.21
Bell, M. B. V., Nichols, H. J., Gilchrist, J. S., Cant, M. A., and Hodge, S. J. (2011). The cost of dominance: suppressing subordinate reproduction affects the reproductive success of dominant female banded mongooses. Proc. R. Soc. Lond. B 279, 619-624. doi: 10.1098/rspb.2011.1093

Cain, K. E., and Ketterson, E. D. (2012). Competitive females are successful females; phenotype, mechanism and selection in a common songbird. Behav. Ecol. Sociobiol. 66, 241-252. doi: 10.1007/s00265011-1272-5

Cain, K. E., and Ketterson, E. D. (2013). Costs and benefits of competitive traits in females: aggression, maternal care and reproductive success. PLoS ONE 8:e77816. doi: 10.1371/journal.pone.0077816

Clutton-Brock, T. H. (2009). Sexual selection in females. Anim. Behav. 77, 3-11. doi: 10.1016/j.anbehav.2008.08.026

Gerlach, N. M., and Ketterson, E. D. (2013). Experimental elevation of testosterone lowers fitness in female dark-eyed juncos. Horm. Behav. 63, 782-790. doi: 10.1016/j.yhbeh.2013.03.005

Hamilton, W. D., and Zuk, M. (1982). Heritable true fitness and bright birds: a role for parasites? Science 218, 384-387. doi: 10.1126/science.71 23238

LeBas, N. R. (2006). Female finery is not for males. Trends. Ecol. Evol. 21, 170-173. doi: 10.1016/j.tree.2006.01.007

Rosvall, K. A. (2011a). Intrasexual competition in females: evidence for sexual selection? Behav. Ecol. 22, 1131-1140. doi: 10.1093/beheco/arr106

Rosvall, K. A. (2011b). Maintenance of variation in sexually selected traits in females: a case study using intrasexual aggression in tree swallows Tachycineta bicolor. J. Avian Biol. 42, 454-462. doi: 10.1111/j.1600-048X.2011.05322.x

Rubenstein, D. R. (2012). Sexual and social competition: broadening perspectives by defining female roles. [Theme issue]. Philos. Trans. R. Soc. Lond. B Biol. Sci. 367, 2248-2375. doi: 10.1098/rstb. 2011.0278

Simmons, L. W., and Emlen, D. J. (2008). No fecundity cost of female secondary sexual trait expression in the horned beetle Onthophagus sagittarius.
J. Evol. Biol. 21, 1227-1235. doi: 10.1111/j.14209101.2008.01575.x

Stockley, P., and Bro-Jørgensen, J. (2011). Female competition and its evolutionary consequences in mammals. Biol. Rev. 86, 341-366. doi: 10.1111/j.1469-185X.2010.00149.x

Stockley, P., and Campbell, A. (2013). Female competition and aggression [Theme issue]. Philos. Trans. R. Soc. B Biol. Sci. 368.

Tobias, J. A., Montgomerie, R., and Lyon, B. E. (2012). The evolution of female ornaments and weaponry: social selection, sexual selection and ecological competition. Philos. Trans. R. Soc. B Biol. Sci. 367, 2274-2293. doi: 10.1098/rstb. 2011.0280

West-Eberhard, M. J. (1983). Sexual selection, social competition, and speciation. Q. Rev. Biol. 58, 155-183. doi: 10.1086/413215

Zahavi, A. (1975). Mate selection-a selection for a handicap. J. Theor. Biol. 53, 205-214. doi: 10.1016/0022-5193(75)90111-3

Conflict of Interest Statement: The authors declare that the research was conducted in the absence of any commercial or financial relationships that could be construed as a potential conflict of interest.

Received: 02 May 2014; accepted: 18 June 2014; published online: 08 July 2014.

Citation: Cain KE and Rosvall KA (2014) Next steps for understanding the selective relevance of female-female competition. Front. Ecol. Evol. 2:32. doi: 10.3389/fevo. 2014.00032

This article was submitted to Behavioral and Evolutionary Ecology, a section of the journal Frontiers in Ecology and Evolution.

Copyright (c) 2014 Cain and Rosvall. This is an openaccess article distributed under the terms of the Creative Commons Attribution License (CC BY). The use, distribution or reproduction in other forums is permitted, provided the original author(s) or licensor are credited and that the original publication in this journal is cited, in accordance with accepted academic practice. No use, distribution or reproduction is permitted which does not comply with these terms. 